OPEN ACCESS

Edited by:

Éva Hideg,

University of Pécs, Hungary

Reviewed by:

Jean-David Rochaix,

Université de Genève, Switzerland

Alexander G. Ivanov,

Bulgarian Academy of Sciences,

Bulgaria

*Correspondence:

Joaquim A. G. Silveira

silveira@ufc.br

Peter J. Gollan

petgo/@utu.fi;

peter.gollan@utu.fi

Specialty section:

This article was submitted to

Plant Abiotic Stress,

a section of the journal

Frontiers in Plant Science

Received: 08 March 2019

Accepted: 28 June 2019

Published: 12 July 2019

Citation:

Lima-Melo Y, Alencar VTCB, Lobo AKM, Sousa RHV, Tikkanen M, Aro E-M, Silveira JAG and Gollan PJ (2019) Photoinhibition of Photosystem I Provides Oxidative Protection During Imbalanced Photosynthetic Electron

Transport in Arabidopsis thaliana.

Front. Plant Sci. 10:916.

doi: 10.3389/fpls.2019.00916

\section{Photoinhibition of Photosystem I Provides Oxidative Protection During Imbalanced Photosynthetic Electron Transport in Arabidopsis thaliana}

\author{
Yugo Lima-Melo ${ }^{1,2}$, Vicente T. C. B. Alencar ${ }^{1}$, Ana K. M. Lobo ${ }^{1}$, Rachel H. V. Sousa1, \\ Mikko Tikkanen ${ }^{2}$, Eva-Mari Aro ${ }^{2}$, Joaquim A. G. Silveira ${ }^{1 *}$ and Peter J. Gollan ${ }^{2 *}$
}

${ }^{1}$ Department of Biochemistry and Molecular Biology, Federal University of Ceará, Fortaleza, Brazil, ${ }^{2}$ Molecular Plant Biology, Department of Biochemistry, University of Turku, Turku, Finland

Photosynthesis involves the conversion of sunlight energy into stored chemical energy, which is achieved through electron transport along a series of redox reactions. Excess photosynthetic electron transport might be dangerous due to the risk of molecular oxygen reduction, generating reactive oxygen species (ROS) over-accumulation. Avoiding excess ROS production requires the rate of electron transport to be coordinated with the capacity of electron acceptors in the chloroplast stroma. Imbalance between the donor and acceptor sides of photosystem I (PSI) can lead to inactivation, which is called PSI photoinhibition. We used a light-inducible PSI photoinhibition system in Arabidopsis thaliana to resolve the time dynamics of inhibition and to investigate its impact on ROS production and turnover. The oxidation state of the PSI reaction center and rates of $\mathrm{CO}_{2}$ fixation both indicated strong and rapid PSI photoinhibition upon donor side/acceptor side imbalance, while the rate of inhibition eased during prolonged imbalance. PSI photoinhibition was not associated with any major changes in ROS accumulation or antioxidant activity; however, a lower level of lipid oxidation correlated with lower abundance of chloroplast lipoxygenase in PSI-inhibited leaves. The results of this study suggest that rapid activation of PSI photoinhibition under severe photosynthetic imbalance protects the chloroplast from over-reduction and excess ROS formation.

Keywords: photosystem I, photosynthesis, $\mathrm{ROS}, \mathrm{CO}_{2}$ fixation, photoinhibition, P700, redox

\section{INTRODUCTION}

Light is vital for photosynthesis, but when supplied in excess it can damage the photosynthetic apparatus and cause photo-oxidative stress. This condition occurs during states of photosynthetic imbalance, when the electron pressure in the photosynthetic electron transport chain exceeds the capacity of reducing power consumption by sink pathways, which is usually associated with stressful environmental conditions. As a result, transient or sustained production of reactive oxygen species (ROS) can occur. Excessive accumulation of ROS can impair metabolic homeostasis through oxidative damage to cells because of their high reactivity with lipids, proteins, and nucleic acids (McCord, 2000; Apel and Hirt, 2004; Munns, 2005; Sharma et al., 2012). On the other hand, 
ROS play an important role in signaling pathways essential for acclimation to environmental conditions (for recent reviews, see Mittler, 2017; Czarnocka and Karpiński, 2018; Mullineaux et al., 2018). ROS can induce signaling responses directly, or indirectly by driving redox changes that modulate signaling networks (de Souza et al., 2017; Exposito-Rodriguez et al., 2017; Noctor et al., 2018; Souza et al., 2018). In addition, oxidation by-products, including oxidized lipids and pigments, transduce signals (Mueller et al., 2008; Mosblech et al., 2009; López et al., 2011; Ramel et al., 2012; Satoh et al., 2014). Because ROS are harmful at high concentrations, but at the same time are important for signaling and plant acclimation, the precise control of ROS concentrations is critical for metabolic homeostasis. Accordingly, plants control photosynthetic ROS production by regulating light-harvesting and electron transport (reviewed in Tikkanen and Aro, 2014), in particular through protonation of the thylakoid lumen that requires the proton gradient regulation 5 (PGR5) protein (Munekage et al., 2002; Suorsa et al., 2012). In the chloroplast stroma, ROS concentrations are regulated by antioxidant systems involving numerous redox enzymes, including the superoxide dismutases (SOD), which catalyze the dismutation of superoxide radical $\left(\mathrm{O}_{2}^{\bullet-}\right)$ to hydrogen peroxide $\left(\mathrm{H}_{2} \mathrm{O}_{2}\right)$, that in turn can be subsequently reduced to water by ascorbate peroxidases (APX) and other peroxidases through the Foyer-Halliwell-Asada cycle, using ascorbate (ASC), glutathione (GSH) and thioredoxins as electron donors (Asada, 1999; Foyer and Shigeoka, 2011).

A central consequence of photo-oxidative stress is inactivation of the photosystems, a phenomenon known as "photoinhibition" (reviewed in Aro et al., 1993; Gururani et al., 2015). Photoinhibition decreases photosynthetic capacity and can therefore be deleterious to plant growth and yield (Takahashi and Murata, 2008; Kato et al., 2012; Simkin et al., 2017). Photosystem I (PSI) is particularly resistant to photoinhibition under oxidative stress conditions, due to the high efficacy of protective mechanisms that regulate the flow of electrons to the PSI donor side, including non-photochemical quenching (NPQ), lumen $\mathrm{pH}$-dependent regulation of cytochrome $b 6 f$ activity, and even PSII photoinhibition (reviewed in Tikkanen and Aro, 2014). Electron consumption at the PSI acceptor side through the Calvin-Benson cycle, photorespiration, cyclic and pseudo-cyclic electron flow are also protective factors that prevent PSI over-reduction (Yamori, 2016; Li et al., 2018).

Despite this, PSI photoinhibition occurs under specific conditions of excessive electron pressure from PSI electron donors on the lumenal side, or/and insufficient capacity of electron acceptors at the stromal side. Under these stress conditions, reduction of $\mathrm{O}_{2}$ produces $\mathrm{O}_{2}^{\bullet-}$ that can inactivate PSI iron-sulfur (FeS) clusters and cause PSI inhibition (Sonoike and Terashima, 1994; Sonoike, 1995; Takagi et al., 2016; Tiwari et al., 2016). In contrast to PSII, the recovery of inhibited PSI has been shown to occur very slowly, over several days (Barth et al., 2001; Kudoh and Sonoike, 2002; Huang et al., 2010; LimaMelo et al., 2019). PSI photoinhibition in wild type plants has been observed under low irradiance at chilling temperatures, due to down-regulation of stromal electron sinks (Inoue et al., 1986; Terashima et al., 1994; Tjus et al., 1998; Zhang and Scheller, 2004) as well as under fluctuating light (Kono et al., 2014). On the other hand, resistance against PSI photoinhibition can be induced by acclimation to low temperature and high light conditions (Ivanov et al., 1998, 2012). Severe PSI photoinhibition can occur when $\mathrm{pH}$-dependent control of electron transport is inactivated, such as in plants lacking the PGR5 protein (Munekage et al., 2002; Nandha et al., 2007; Suorsa et al., 2012; Tiwari et al., 2016). High light treatment of the pgr5 mutant of Arabidopsis thaliana has provided an inducible model for PSI inhibition that has been used to study the mechanisms of PSI damage and the impacts of PSI photoinhibition on photosynthesis and metabolism of plants (Tiwari et al., 2016; Gollan et al., 2017; Lima-Melo et al., 2019). Exposure of pgr5 to sudden increases in light intensity causes PSI FeS cluster damage (Tiwari et al., 2016) and degradation of PSI subunit proteins (Suorsa et al., 2012; Lima-Melo et al., 2019).

Although several studies have shown that PSI photoinhibition is triggered by ROS (Sonoike and Terashima, 1994; Sonoike, 1995; Sejima et al., 2014; Takagi et al., 2016), the correlation between PSI photoinhibition and ROS metabolism is not clear. In the current study, we investigated the dynamics of PSI photoinhibition in pgr5 mutants under high light stress, and the relationship between PSI photoinhibition and ROS accumulation associated with occurrence of oxidative stress at the whole leaf level. Our data suggest that PSI photoinhibition is a mechanism to prevent excessive ROS production in order to minimize oxidative stress, at the expense of carbon assimilation and normal growth.

\section{MATERIALS AND METHODS}

\section{Plants, Growth and Treatment Conditions}

The proton gradient regulation 5 (pgr5) mutant plants of A. thaliana L. Heynh. ecotype Columbia, which are in the glabrous 1 genetic background (Munekage et al., 2002), were used alongside wild-type (WT) glabrous 1 plants in all experiments. Plants were grown for 6 weeks in a growth chamber at $23^{\circ} \mathrm{C}$, relative humidity $60 \%, 8 / 16 \mathrm{~h}$ of light/dark photoperiod under constant white light of $125 \mu \mathrm{mol}$ photons $\mathrm{m}^{-2} \mathrm{~s}^{-1}$ (GL). For high light (HL) treatments, plants were shifted from GL to $1,000 \mu \mathrm{mol}$ photons $\mathrm{m}^{-2} \mathrm{~s}^{-1}$ for $1 \mathrm{~h}$, while control groups were kept under GL. Experiments were repeated at least twice and at least three independent replicates were used in every experiment.

\section{Photochemical and Gas Exchange Measurements}

Photosystem II and photosystem I photochemistry were measured simultaneously using a Dual-PAM-100 system (Walz, Germany) based on chlorophyll a fluorescence (Schreiber et al., 1995) and P700 absorbance (Klughammer and Schreiber, 1998). Detached leaves were analyzed after $30 \mathrm{~min}$ of dark acclimation. Gas exchange measurements (net $\mathrm{CO}_{2}$ assimilation, $A$; transpiration, $E$; stomatal conductance, $g_{S}$; and internal $\mathrm{CO}_{2}$ concentration, $\mathrm{Ci}$ ) were performed in detached leaves after 15 min dark acclimation, using a LI-6400XT Portable Infrared Gas Analyzer (IRGA) equipped with an LED source (LI-COR Biosciences, United States). The environmental conditions inside 
the IRGA chamber were: $400 \mathrm{ppm} \mathrm{CO}_{2}, 1.0 \pm 0.2 \mathrm{kPa} \mathrm{VPD}$ and $25^{\circ} \mathrm{C}$. For the net $\mathrm{CO}_{2}$ assimilation $(A)$ time-course assay, $A$ was recorded every $15 \mathrm{~s}$ during changes of light intensity between GL and HL with the following protocol: $15 \mathrm{~min}$ of dark, $30 \mathrm{~min}$ of GL, $60 \mathrm{~min}$ of HL, $60 \mathrm{~min}$ of GL, $30 \mathrm{~min}$ of HL. For rapid light curves, a PPFD gradient of five increasing steps $\left(0,50,125,500\right.$, and $1,000 \mu \mathrm{mol}$ photons $\left.\mathrm{m}^{-2} \mathrm{~s}^{-1}\right)$ was used. Gas exchange data were logged after IRGA parameters reached steady-state values after the start of each light intensity (usually around $120 \mathrm{~s}$ ). The water use efficiency (WUE) and the maximum carboxylation efficiency were calculated as $A / E$ and $A / C \mathrm{i}$, respectively.

\section{Leaf Membrane Damage and $\mathrm{H}_{2} \mathrm{O}_{2}$ Content}

Leaf membrane damage (MD) was estimated through the electrolyte leakage method (Blum and Ebercon, 1981). Detached leaves (5 plants, 2 leaves from each plant) were placed in tubes containing deionized water and incubated in a shaking water bath at $25^{\circ} \mathrm{C}$ for $24 \mathrm{~h}$. After measuring electric conductivity (L1), the solution was heated at $95^{\circ} \mathrm{C}$ for $1 \mathrm{~h}$ and then cooled to $25^{\circ} \mathrm{C}$, after which the second electric conductivity (L2) was measured. Membrane damage was calculated as $\mathrm{MD}=(\mathrm{L} 1 / \mathrm{L} 2) \times 100$. The $\mathrm{H}_{2} \mathrm{O}_{2}$ content was quantified using the Amplex Red Hydrogen Peroxide/Peroxidase Assay Kit (Life Technologies, Carlsbad, CA, United States) according to the manufacturer protocols. Fresh leaves were ground to a fine powder in liquid $\mathrm{N}_{2}$ followed by the addition of potassium phosphate buffer (final concentration of $100 \mathrm{mM} ; \mathrm{pH}$ 7.5). The absorbance at $560 \mathrm{~nm}$ was measured to quantify the $\mathrm{H}_{2} \mathrm{O}_{2}$ concentration (Zhou et al., 1997) and results were expressed as $\mu \mathrm{mol} \mathrm{H}_{2} \mathrm{O}_{2} \mathrm{~g}^{-1}$ fresh weight $(\mathrm{FW})$.

\section{Histochemical Detection of Superoxide and Hydrogen Peroxide}

Nitroblue tetrazolium (NBT) and diaminobenzidine (DAB) staining were performed for in situ detection of superoxide $\left(\mathrm{O}_{2}^{\bullet-}\right)$ and hydrogen peroxide $\left(\mathrm{H}_{2} \mathrm{O}_{2}\right)$ accumulation, respectively, in leaves, as previously described (Ogawa et al., 1997; Thordal-Christensen et al., 1997). High light-treated leaves were detached and submerged in tubes containing DAB solution [4.67 mM DAB; $1 \%$ isopropanol $(\mathrm{v} / \mathrm{v})$ and $0.1 \%$ Triton $(\mathrm{v} / \mathrm{v})]$ or NBT solution $[0.1 \%$ NBT $(\mathrm{m} / \mathrm{v})$ and $10 \mathrm{mM} \mathrm{NaN}$ in $10 \mathrm{mM}$ potassium phosphate buffer, $\mathrm{pH}$ 7.8], both protected from light, and incubated for $24 \mathrm{~h}$. For NBT staining, leaves were moved to petri dishes containing water and treated with light (approximately $20 \mu \mathrm{mol} \mathrm{m} \mathrm{m}^{-2}$ $\mathrm{s}^{-1}$ ) for $30 \mathrm{~min}$ prior to the end of the $24 \mathrm{~h}$ incubation. DABand NBT-stained leaves were then incubated in a bleaching solution [TCA $0.15 \%(\mathrm{~m} / \mathrm{v})$ diluted in ethanol:chloroform $(4: 1 \mathrm{v} / \mathrm{v})]$ for $48 \mathrm{~h}$. Stained leaves were then submerged in $80 \%$ ethanol and heated $\left(70^{\circ} \mathrm{C}\right)$ in a water bath for $15 \mathrm{~min}$, followed by several washes with $80 \%$ ethanol until complete removal of pigments. Leaves were then dried and photographed.

\section{Lipid Peroxidation (TBARS Content and Autoluminescence Imaging)}

Lipid peroxidation was estimated according to the formation of thiobarbituric acid-reactive substances (TBARS; Heath and Packer, 1968). Fresh leaves were ground to a fine powder in liquid $\mathrm{N}_{2}$ followed by the addition of TCA [final concentration of 5\% $(w / v)]$. After centrifugation at $12,000 \times g$ for $15 \mathrm{~min}, 500 \mu \mathrm{l}$ of the supernatants were immediately diluted in $2 \mathrm{ml}$ of a solution containing $0.5 \%(\mathrm{w} / \mathrm{v})$ of thiobarbituric acid (TBA) and $20 \%$ $(\mathrm{w} / \mathrm{v})$ of TCA and heated at $95^{\circ} \mathrm{C}$ in a water bath for $1 \mathrm{~h}$. After cooling to $25^{\circ} \mathrm{C}$, the solutions were centrifuged at $10,000 \times g$ for $5 \mathrm{~min}$ and supernatants were collected for absorbance readings at 532 and $660 \mathrm{~nm}$ using a spectrophotometer. The absorption values at $660 \mathrm{~nm}$ obtained from blank samples without leaf tissue were subtracted. The concentration of TBARS was calculated using the absorption coefficient of the thiobarbituric acid-malondialdehyde complex (TBA-MDA), which is $155 \mathrm{mM}^{-1} \mathrm{~cm}^{-1}$, and the results were expressed as nmol TBA-MDA $\mathrm{g}^{-1} \mathrm{FW}$. Lipid peroxidation was also assessed by the autoluminescence of leaves and rosettes according to the method described in Birtic et al. (2011). Detached leaves or rosettes treated with GL (control), HL or physical wounding with forceps were incubated in darkness for $2 \mathrm{~h}$ before the luminescence signal was collected over $20 \mathrm{~min}$ on an electrically cooled chargedcouple device (CCD) camera, using an IVIS Lumina II system (Caliper Life Sciences, United States).

\section{Protein Extraction and Enzymatic Activity Assays}

Fresh leaves were ground to a fine powder in liquid $\mathrm{N}_{2}$ followed by the addition of potassium phosphate buffer (final concentration of $100 \mathrm{mM}$; pH 7.0) containing EDTA (final concentration of $1 \mathrm{mM}$ ). The homogenate was centrifuged at $15,000 \times g$ at $4^{\circ} \mathrm{C}$ for $15 \mathrm{~min}$, and the resulting supernatant was used for determination of all enzymatic activities. Total soluble protein content was measured according to Bradford (1976), and all the activities were expressed on the basis of protein. All enzymatic activities were determined spectrophotometrically. Superoxide dismutase (SOD; EC 1.15.1.1) activity was determined based on inhibition of nitro blue tetrazolium chloride (NBT) photoreduction (Giannopolitis and Reis, 1977). The reaction mixture contained $75 \mu \mathrm{M}$ NBT, $20 \mu \mathrm{M}$ riboflavin, and $100 \mu \mathrm{l}$ of the protein extract, all diluted in $50 \mathrm{mM}$ potassium phosphate buffer ( $\mathrm{pH}$ 6.0) containing $1 \mathrm{mM}$ EDTA in a final volume of $2 \mathrm{ml}$, which was incubated under illumination $\left(30 \mu \mathrm{mol}\right.$ photons $\mathrm{m}^{-2} \mathrm{~s}^{-1}$ ) at $25^{\circ} \mathrm{C}$ for $5 \mathrm{~min}$. The absorbance was measured at $540 \mathrm{~nm}$. One SOD activity unit (U) was defined as the amount of enzyme required to inhibit $50 \%$ of the NBT photoreduction, expressed as $\mathrm{U} \mathrm{mg}^{-1}$ protein $\mathrm{min}^{-1}$. Catalase (CAT; EC 1.11.1.6) activity was based on the reduction of $\mathrm{H}_{2} \mathrm{O}_{2}$ (Beers and Sizer, 1952; Havir and McHale, 1987). The reaction mixture contained $20 \mathrm{mM} \mathrm{H}_{2} \mathrm{O}_{2}$, and $25 \mu \mathrm{l}$ of the protein extract, all diluted in $50 \mathrm{mM}$ potassium phosphate buffer (pH 7.0) in a final volume of $1.5 \mathrm{ml}$. The reaction was started by adding the protein extract and the decrease in absorbance at $240 \mathrm{~nm}$ at $30^{\circ} \mathrm{C}$ was monitored for $300 \mathrm{~s}$. CAT activity 
was calculated using the molar extinction coefficient of $\mathrm{H}_{2} \mathrm{O}_{2}$ $\left(40 \mathrm{mM}^{-1} \mathrm{~cm}^{-1}\right)$ and expressed as $\mu \mathrm{mol} \mathrm{H} \mathrm{H}_{2} \mathrm{mg}^{-1}$ protein $\min ^{-1}$. APX (EC 1.11.1.11) activity was measured based on the oxidation of ascorbate (ASC) (Nakano and Asada, 1981) in a reaction mixture containing $0.45 \mathrm{mM}$ ASC, $3 \mathrm{mM} \mathrm{H}_{2} \mathrm{O}_{2}$, and $50 \mu \mathrm{l}$ of the protein extract, all diluted in $100 \mathrm{mM}$ potassium phosphate buffer ( $\mathrm{pH} 7.0$ ) containing $1 \mathrm{mM}$ EDTA in a final volume of $1.5 \mathrm{ml}$. The reaction was started by adding the $\mathrm{H}_{2} \mathrm{O}_{2}$ solution and the decrease in absorbance at $290 \mathrm{~nm}$ at $25^{\circ} \mathrm{C}$ was monitored for $300 \mathrm{~s}$. APX activity was expressed as $\mu \mathrm{mol}$ ASC $\mathrm{mg}^{-1}$ protein $\mathrm{min}^{-1}$. Monodehydroascorbate reductase (MDHAR; EC 1.6.5.4) activity was assayed based on the generation of monodehydroascorbate (MDHA) free radicals by ascorbate oxidase (AO; 1.10.3.3) and following oxidation of NADH (Hossain et al., 1984) in a reaction mixture containing $0.1 \mathrm{mM} \mathrm{NADH}, 2.5$ ASC, 0.84 units/ml AO, and $75 \mu \mathrm{l}$ of the protein extract. The reaction mixture was adjusted to $725 \mu \mathrm{l}$ with $50 \mathrm{mM}$ Tris- $\mathrm{HCl}$ buffer ( $\mathrm{pH}$ 7.6). The reaction was started by adding the $\mathrm{AO}$ solution and the decrease in absorbance at $340 \mathrm{~nm}$ at $25^{\circ} \mathrm{C}$ was monitored for $300 \mathrm{~s}$. MDHAR activity was calculated using the extinction coefficient of $\mathrm{NADH}$ $\left(6.2 \mathrm{mM}^{-1} \mathrm{~cm}^{-1}\right)$ and expressed as nmol NADH $\mathrm{mg}^{-1}$ protein $\min ^{-1}$. Dehydroascorbate reductase (DHAR; EC 1.8.5.1) activity was assayed based on the oxidation of GSH (Nakano and Asada, 1981) in a reaction mixture containing $2.5 \mathrm{mM}$ GSH, $0.2 \mathrm{mM}$ dehydroascorbate (DHA), and $50 \mu \mathrm{l}$ of the protein extract, all diluted in $50 \mathrm{mM}$ potassium phosphate ( $\mathrm{pH}$ 7.0) in a final volume of $1.5 \mathrm{ml}$. The reaction was started by adding the DHA solution and the increase in absorbance at $265 \mathrm{~nm}$ at $25^{\circ} \mathrm{C}$ was monitored for 300 s. DHAR activity was expressed as nmol NADH mg $\mathrm{m}^{-1}$ protein $\min ^{-1}$.

\section{Gene Expression Analysis}

Plants were treated with GL and HL, after which leaves were detached and frozen in liquid $\mathrm{N}_{2}$. Leaf samples contained four leaves from individual plants. Frozen leaves were ground to a powder in liquid $\mathrm{N}_{2}$ and total RNA was purified using TRIsure (Bioline, United States), according to the protocol supplied, with an additional final purification in $2.5 \mathrm{M} \mathrm{LiCl}$ overnight at $-20^{\circ} \mathrm{C}$. RNAseq libraries were constructed, and libraries were sequenced in 50 bp single-end reads using Illumina Hiseq 2500 technology (BGI Tech Solutions, Hong Kong). Reads were aligned to the reference genome (A. thaliana TAIR 10) using Strand NGS 2.7 software (Agilent, United States). Aligned reads were normalized and quantified using the DESeq $\mathrm{R}$ package. Gene expression fold changes were calculated using a two-way ANOVA test on triplicate samples $(n=3)$ with BenjaminiHochberg $p$-value correction to determine the false discovery rate (FDR) for each gene.

\section{Western Blotting}

Leaf tissue was ground to a powder in liquid nitrogen and then incubated in $20 \mathrm{mM}$ Tris buffer $(\mathrm{pH} 7.8)$ containing $2 \%$ SDS for $20 \mathrm{~min}$ at $37^{\circ} \mathrm{C}$, followed by $5 \mathrm{~min}$ centrifugation at $15,000 \times g$. The supernatant containing total leaf protein was used for Western blotting. $10 \mu \mathrm{g}$ of total protein were separated on SDS-PAGE gels containing 12\% acrylamide, transferred to polyvinylidene difluoride (PVDF) membranes and blotted with polyclonal antibodies against LOX-C antiserum (AS07 258; Agrisera).

\section{RESULTS}

\section{High Light Rapidly Induces PSI Photoinhibition in pgr5 Mutants}

Photosynthetic parameters were monitored in leaves of wildtype (WT) and pgr5 mutant plants that were grown under $125 \mu \mathrm{mol}$ photons $\mathrm{m}^{-2} \mathrm{~s}^{-1}$ (growth light; GL) and then exposed to $1,000 \mu \mathrm{mol}$ photons $\mathrm{m}^{-2} \mathrm{~s}^{-1}$ (high light; HL). Chlorophyll $a$ fluorescence and P700 absorbance were measured during $5 \mathrm{~h}$ HL treatments. The PSI photoinhibition levels were estimated through the evaluation of the maximum oxidation of P700 at the PSI reaction center $\left(P_{m}\right)$. Before the HL treatment, the average $P_{m}$ value of WT leaves (1.2) was almost 30\% higher than that of pgr5 leaves (0.85; see $0 \mathrm{~h}$ in Figure 1A). The $P_{m}$ value of WT leaves remained virtually unchanged through the $5 \mathrm{~h}$ HL treatment, whereas the same parameter in pgr5 decreased to $60 \%$ of the pre-treatment level after only 15 min under HL, with further decreases to 45 and $35 \%$ after $30 \mathrm{~min}$ and $1 \mathrm{~h} \mathrm{HL}$, respectively. $P_{m}$ in HL-treated pgr5 reached a steady-state value of around 0.15 (20\% of pre-treatment $P_{m}$ ) after $3 \mathrm{~h}$ of HL treatment.

PSII photoinhibition was evaluated by monitoring the decrease of the maximum chlorophyll a fluorescence $\left(F_{m}\right)$ during the same time-course experiment. The $F_{m}$ values before the onset of the HL treatment were almost identical in WT and pgr5 (Figure 1B). After $15 \mathrm{~min}, F_{m}$ values decreased to 0.75 and 0.65 in $\mathrm{WT}$ and pgr5, respectively, and then showed a steady decline over the course of the $5 \mathrm{~h} \mathrm{HL}$ treatment in both genotypes. In contrast, the HL-induced decline in the calculated $F_{v} / F_{m}$ (maximum quantum efficiency of PSII) parameter was substantially greater in the pgr5 mutant (Figure 1C), which corresponded to significantly higher levels of minimum chlorophyll $a$ fluorescence $\left(F_{o}\right)$ after $30 \mathrm{~min} \mathrm{HL}$ exposure, when compared to WT (Figure 1D).

\section{Time-Resolved Diminution of $\mathrm{CO}_{2}$ Assimilation During PSI Photoinhibition}

In order to investigate the consequences of progressive HLinduced photoinhibition of PSI on net $\mathrm{CO}_{2}$ assimilation rate $(A)$ and respiration in WT and pgr5 mutant plants, these processes were evaluated during cycles of GL and HL exposure (Figure 2). In both genotypes, similar rates of $\mathrm{CO}_{2}$ assimilation and daytime respiration (measured by $\mathrm{CO}_{2}$ evolution in the dark) were observed in GL-treated plants (Figure 2A). During the first minutes of the transition from GL to HL, $A$ increased at a rate of approximately 1.6-1.7 $\mu \mathrm{mol} \mathrm{CO}_{2} \mathrm{~m}^{-2} \mathrm{~s}^{-1}$ per min in both WT and pgr5 plants (Figure 2B). After approximately $10 \mathrm{~min}$ in HL, WT $A$ decreased until the end of the first hour of HL treatment at a rate of approximately $0.03 \mu \mathrm{mol} \mathrm{CO} \mathrm{m}^{-2} \mathrm{~s}^{-1}$ per min, while $A$ decline in pgr5 during the HL treatment was far more rapid than in the WT, especially during the early phase of $\mathrm{HL}$ exposure $\left(0.11 \mu \mathrm{mol} \mathrm{CO} \mathrm{m}^{-2} \mathrm{~s}^{-1}\right.$ per min) compared to 


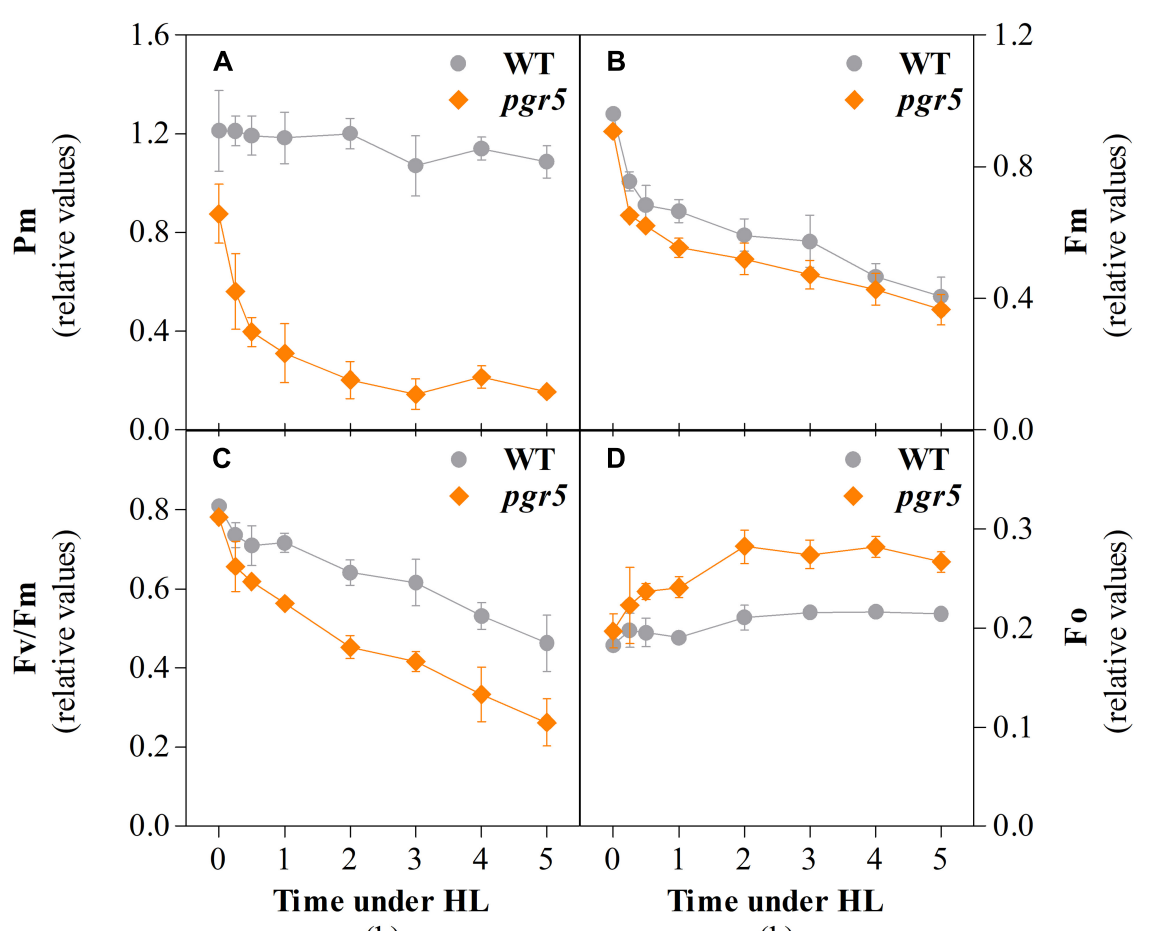

(h)

(h)

FIGURE 1 | Parameters associated with PSI and PSII integrity in wild type (WT) and pgr5 mutants during treatment with high light (HL). Maximum oxidizable P700 $\left(P_{m}, \mathbf{A}\right)$; maximum chlorophyll a fluorescence $\left(F_{m}, \mathbf{B}\right)$; maximum efficiency of PSIl $\left(F_{v} / F_{m}, \mathbf{C}\right)$; minimum chlorophyll a fluorescence $\left(F_{o}, \mathbf{D}\right)$ measured in detached leaves of WT and pgr5 plants grown under a photosynthetic photon flux density of $125 \mu \mathrm{mol} \mathrm{m}{ }^{-2} \mathrm{~s}^{-1}$ and treated with $1,000 \mu \mathrm{mol} \mathrm{m}^{-2} \mathrm{~s}^{-1}$ for $5 \mathrm{~h}$. Error bars show standard deviation among replicates $(n=4)$. Significant differences between genotypes are indicated by non-overlapping error bars (Student's $t$-test, $p<0.05)$.

the latter phase $\left(0.05 \mu \mathrm{mol} \mathrm{CO} \mathrm{m}^{-2} \mathrm{~s}^{-1}\right.$ per min) of treatment (Figure 2C). At the end of the $1 \mathrm{~h} \mathrm{HL}$ treatment, $A$ was $40 \%$ lower in pgr5 mutants than in WT (Figures 2A,C). Under a second phase of GL following the HL treatment, $A$ in WT leaves was slightly lower than the level observed in the first GL phase prior to the HL treatment, while the rate in HL-treated pgr5 mutants was approximately $0 \mu \mathrm{mol} \mathrm{CO} \mathrm{m}^{-2} \mathrm{~s}^{-1}$ (Figure 2A). A second $\mathrm{HL}$ treatment after $1 \mathrm{~h}$ GL induced another rapid increase in $\mathrm{CO}_{2}$ fixation for both genotypes, and in each case the maximum initial rates under the second treatment were approximately equivalent to the rates observed before the end of the previous HL treatment (7.5 $\mu \mathrm{mol} \mathrm{CO} 2 \mathrm{~m}^{-2} \mathrm{~s}^{-1}$ in WT and $5 \mu \mathrm{mol} \mathrm{CO} 2 \mathrm{~m}^{-2} \mathrm{~s}^{-1}$ in pgr5), corresponding to approximately $35 \%$ lower $\mathrm{CO}_{2}$ fixation in pgr5 than in WT during the second HL treatment (Figure 2A). Notably, the rate of increase in $A$ during the second HL treatment was slower in both WT and pgr5 (0.13 and $0.16 \mu \mathrm{mol} \mathrm{CO}_{2} \mathrm{~m}^{-2}$ $\mathrm{s}^{-1}$ per min, respectively; Figure 2D) in comparison to the rates of increase during the first HL treatment $(1.74$ and $1.58 \mu \mathrm{mol}$ $\mathrm{CO}_{2} \mathrm{~m}^{-2} \mathrm{~s}^{-1}$ per min, respectively; Figure $\left.2 \mathrm{~B}\right)$. The rate of decline in $A$ during the second HL treatment was similar between WT and pgr5 (Figure 2E), and smaller than that observed during the first HL treatment (Figure 2C).

Analyses of gas exchange in WT and pgr5 plants pre-treated with GL or HL for $1 \mathrm{~h}$ were conducted using light-response curves to investigate the effects of PSI photoinhibition under different irradiances. $\mathrm{CO}_{2}$ assimilation rates over increasing light intensities were similar in both WT and pgr5 plants treated with GL and were substantially decreased in both genotypes after $1 \mathrm{~h}$ HL treatment (Figure 3A). Significantly lower $A$ values were observed in HL-treated pgr5 compared to HLtreated WT, especially in the region of the curve measured under irradiances below $200 \mu \mathrm{mol}$ photons $\mathrm{m}^{-2} \mathrm{~s}^{-1}$ (Figure 3A). Higher internal $\mathrm{CO}_{2}$ concentration $\left(C_{i}\right)$ was recorded in HLtreated pgr5 at the lowest irradiances of the light curve when compared to all other plants, while there were no significant differences in $\mathrm{Ci}$ at high irradiances (Figure 3B). Stomatal conductance $\left(g_{s}\right)$ values were higher in GL-treated pgr5 when compared to GL-treated WT, and were substantially lower in both genotypes after the HL treatment, compared to GL-treated plants (Figure 3C). No differences in $g_{s}$ values between the genotypes were observed after the HL treatment. The changes in transpiration rate $(E)$ over the light curve were similar to that observed for $g_{s}$ (Figure 3D). The trends observed in the maximum carboxylation efficiency $\left(A / C_{i}\right)$-PPFD curve were similar to those in the $A$-PPFD curve (Figures $3 \mathbf{A}, \mathbf{E}$, respectively), although the difference between the HL-treated pgr5 and the other groups was more evident, as a consequence of the higher $C_{i}$ values under low irradiances (Figure 3B). Water use efficiency (WUE) was strikingly lower in the HL-treated pgr5 mutants when measured under low irradiances, compared to the other treatments (Figure 3F), reflecting the very low $A$ measured in those leaves (Figure 3A). 

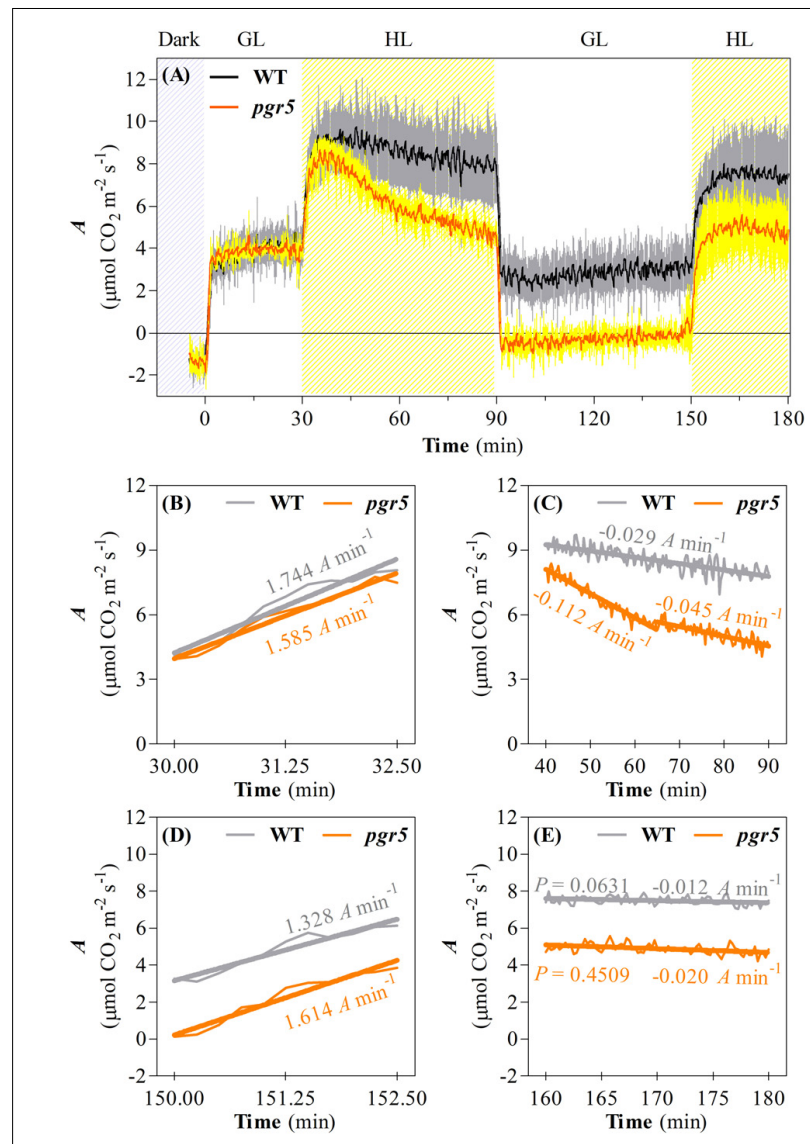

FIGURE 2 | Changes in net $\mathrm{CO}_{2}$ assimilation during a time-course PSI photoinhibition. (A) $\mathrm{CO}_{2}$ assimilation (A) in leaves of WT and pgr5 mutants during changes of light intensity between growth light (GL; $125 \mu \mathrm{mol} \mathrm{m}{ }^{-2}$ $\left.\mathrm{s}^{-1}\right)$ and high light $\left(\mathrm{HL} ; 1,000 \mu \mathrm{mol} \mathrm{m}{ }^{-2} \mathrm{~s}^{-1}\right)$. Hatched gray and hatched yellow sections indicate dark and $\mathrm{HL}$ treatments, respectively. Error margins are shown in gray (WT) and yellow (pgr5) and indicate standard deviation among replicates $(n=6)$. Significant differences between treatments and genotypes are indicated by non-overlapping error bars (Student's $t$-test, $p<0.05)$. Linear regression lines of changes in $A$ drawn in key steps of the time-course like the onset of the first $\mathrm{HL}$ treatment (B), during the first $\mathrm{HL}$ treatment (C), the onset of the second HL treatment (D), and during the second $\mathrm{HL}$ treatment (E). $P$-values were calculated to estimate if the slopes are significantly different from zero. All $P$-values were lower than 0.0001 , except where shown in (E).

\section{ROS Accumulation, and Activities and Expression of Antioxidant Systems After PSI Photoinhibition}

To explore the relationship between PSI photoinhibition and accumulation of ROS, several markers of oxidative stress were evaluated in HL-treated leaves of WT and pgr5 mutants. Membrane damage, estimated through electrolyte leakage, increased significantly after $1 \mathrm{~h}$ of HL treatment in both genotypes, compared to the GL controls; however, no difference was detected between WT and pgr5 mutants in either condition (Figure 4A). Spectrophotometric measurements of $\mathrm{H}_{2} \mathrm{O}_{2}$ concentrations in leaf tissue showed no difference between GL and $1 \mathrm{~h} \mathrm{HL}$ treatments or between genotypes (Figure 4B).

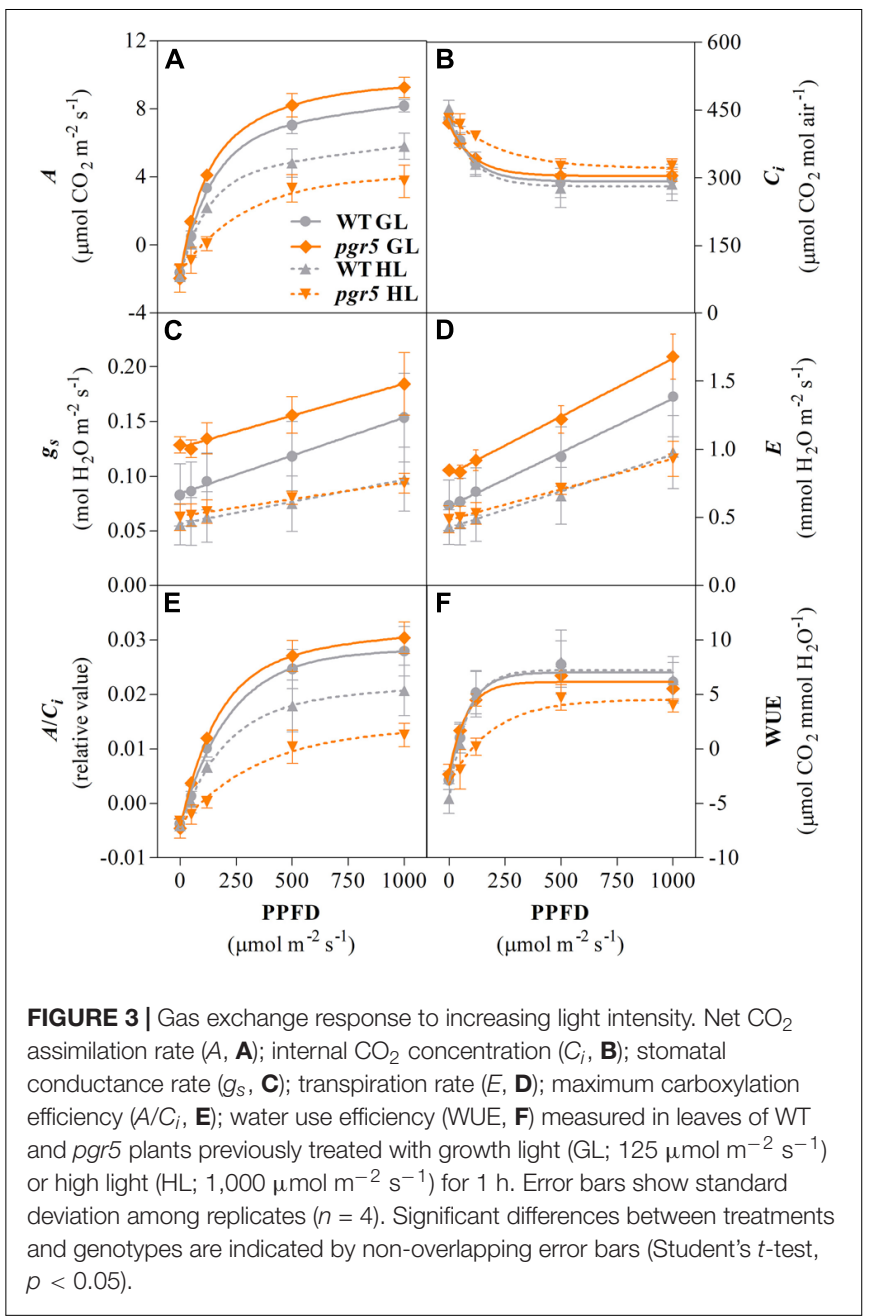

Qualitative in situ assessments of $\mathrm{H}_{2} \mathrm{O}_{2}$ and superoxide $\left(\mathrm{O}_{2}^{--}\right)$ accumulation in HL-treated leaves by 3,3'-diaminobenzidine (DAB) and nitro-blue tetrazolium (NBT) staining, respectively, also showed no obvious differences between WT and pgr5 in terms of accumulation of these ROS (Figures 4C,D).

Activities of SOD, CAT, APX, MDHAR, and DHAR were measured in leaves to assess any effects of PSI photoinhibition on ROS scavenging capacity. Overall, the results showed slightly higher enzyme activities in pgr5, in comparison to WT, in both light conditions (Figure 5). Total leaf CAT activity was significantly higher in pgr5 than in WT under GL (Figure 5B), while total DHAR activity showed a significant increase in HLtreated pgr5, compared to GL-treated pgr5, which was not evident in WT (Figure 5E). Changes in the expression of genes involved in the Foyer-Halliwell-Asada cycle were assessed in WT and pgr5 plants prior to HL treatment, as well as after $15 \mathrm{~min}$ and $1 \mathrm{~h}$ HL exposure. Most genes were upregulated by HL treatment in both WT and pgr 5 plants, with only minor differential expression between genotypes in most cases. Despite the similar trend of HL-induced expression in both genotypes, APX2, DHAR1 and the SOD enzymes CDS1, CDS2, and FSD2, were down-regulated in pgr5 under HL relative to WT levels (Figure 6). Conversely, 


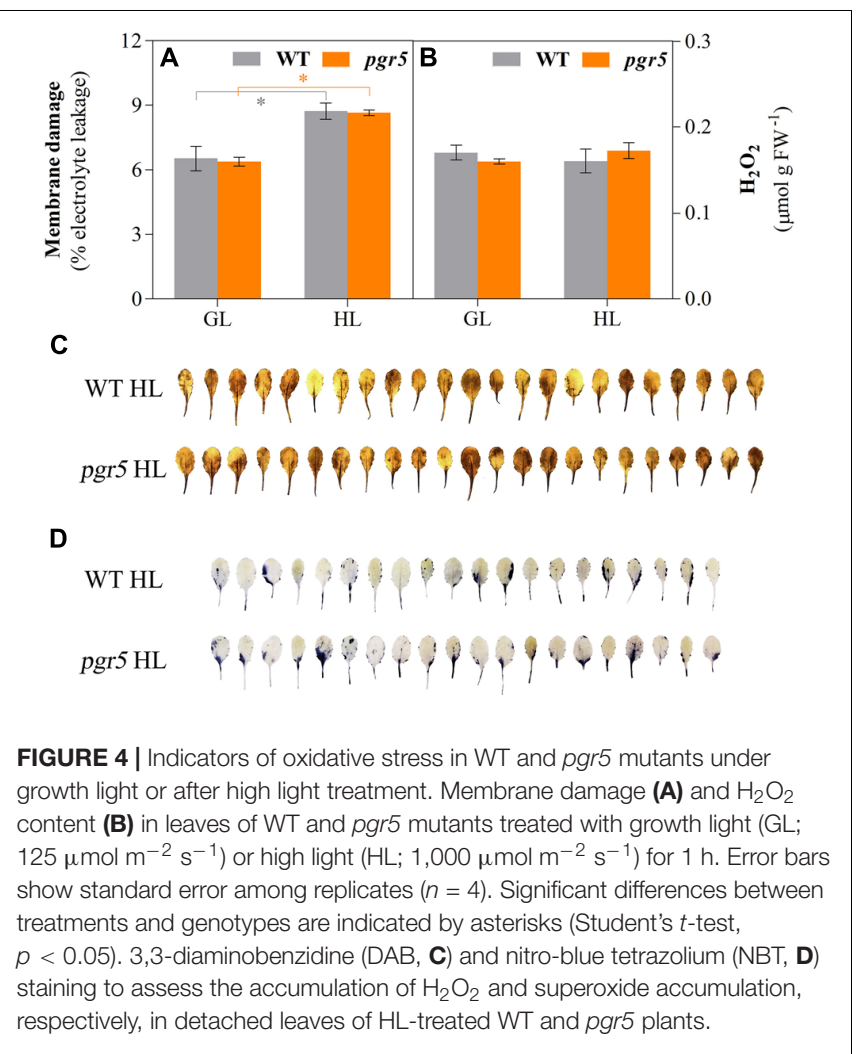

APX1, CAT2 and FSD1 were upregulated in HL-treated pgr5 compared to the WT.

Assessment of thiobarbituric acid-reactive substances (TBARS) content provides an indication of lipid peroxidation. TBARS detected in GL-treated pgr5 did not differ significantly from GL-treated WT, while after $1 \mathrm{~h}$ HL treatment TBARS content in pgr5 was markedly lower than GL and WT levels (Figure 7A). Autoluminescence imaging showed that levels of lipid oxidation in leaves and rosettes increased in WT after $1 \mathrm{~h} \mathrm{HL}$ treatment, in comparison to GL-treated plants, but a corresponding increase was not detected in HL-treated pgr5 (Figures 7B,C). In contrast, strong autoluminescence signals were detected in both genotypes after mechanical wounding of leaves (Figure 7B). Western blots showed increases in the abundance of chloroplast lipoxygenase (LOX2) in both WT and pgr5 after $1 \mathrm{~h}$ HL treatment. However, substantially lower LOX2 abundance was detected in both GL- and HL-treated pgr 5 leaves, in comparison to WT controls (Figure 7D), corroborating the results of TBARS tests (Figure 7A).

\section{DISCUSSION}

Oxidative stress in plants is closely linked to photosynthetic activity, as the transfer of photosynthetic excitation or electrons to oxygen can lead to the overproduction of ROS (for a recent review, see Mullineaux et al., 2018). Excess ROS production resulting from disturbed photosynthetic redox homeostasis is the cause of photodamage to both PSII and PSI, although the mechanisms of damage and repair differ considerably between the two photosystems and distinct intersystem regulation is evident. For example, it has become well established that PSII damage can serve as a photoprotective mechanism by preventing over-reduction and inactivation of downstream factors, especially PSI (Tikkanen et al., 2014; Huang et al., 2016). The current work suggests that rapid PSI photoinhibition under severe photosynthetic imbalance can also prevent excessive ROS production and oxidative damage.

PSI photoinhibition under disturbed redox homeostasis is associated with insufficient stromal acceptor capacity and increased utilization of $\mathrm{O}_{2}$ as an alternative electron acceptor, leading to formation of $\mathrm{O}_{2}^{\bullet-}$ that can inactivate PSI iron-sulfur (FeS) clusters (reviewed in Sonoike, 2011). Protection from PSI photoinhibition is especially dependent on functional $\mathrm{pH}$ dependent regulation of electron flow to PSI during increased irradiance (Suorsa et al., 2012; Kono et al., 2014; Tiwari et al., 2016; Gollan et al., 2017; Lima-Melo et al., 2019; Yamamoto and Shikanai, 2019). In the current work, a large decrease in $P_{m}$ within the first minutes of exposure of pgr5 mutants to HL shows that PSI photoinhibition occurs rapidly upon the onset of imbalance between the PSI donor and acceptor sides. This rapid inhibition suggests that the normal levels of antioxidant activity measured in pgr5 (Figure 5) were not sufficient to mitigate ROS-induced PSI damage within the initial stages of imbalance. These results support other findings that showed that chloroplast antioxidant
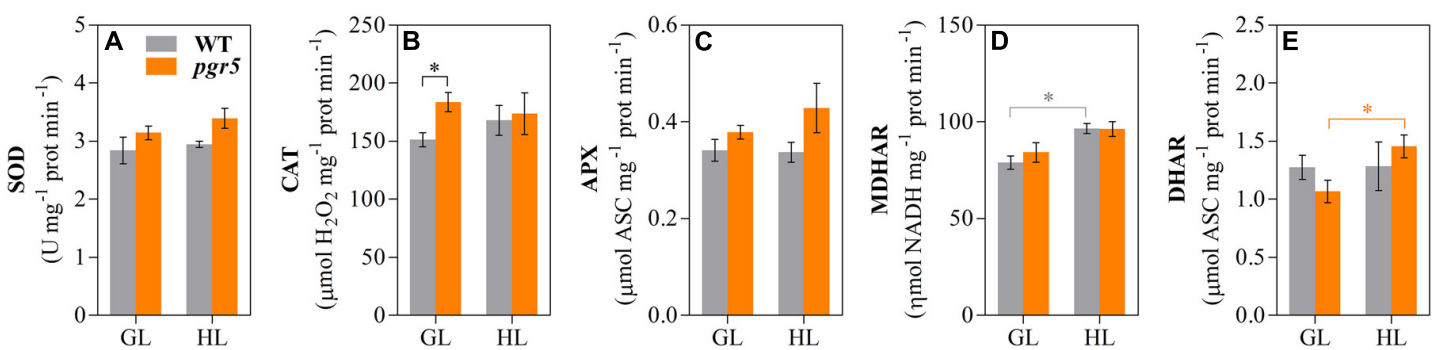

FIGURE 5 | Activities of Foyer-Halliwell-Asada cycle enzymes. Activities of superoxide dismutase (SOD, A); catalase (CAT, B); ascorbate peroxidase (APX, C); monodehydroascorbate reductase (MDHAR, D) and dehydroascorbate reductase (DHAR, E) were measured in total leaf extracts of WT and pgr5 mutants treated with growth light (GL; $125 \mu \mathrm{mol} \mathrm{m} \mathrm{m}^{-2} \mathrm{~s}^{-1}$ ) or high light ( $\mathrm{HL} ; 1,000 \mu \mathrm{mol} \mathrm{m} \mathrm{m}^{-2} \mathrm{~s}^{-1}$ ) for $1 \mathrm{~h}$. Activities are normalized to protein content. Error bars show standard error among replicates $(n=4)$. Significant differences between treatments and genotypes are indicated by asterisks (Student's $t$-test, $p<0.05)$. 


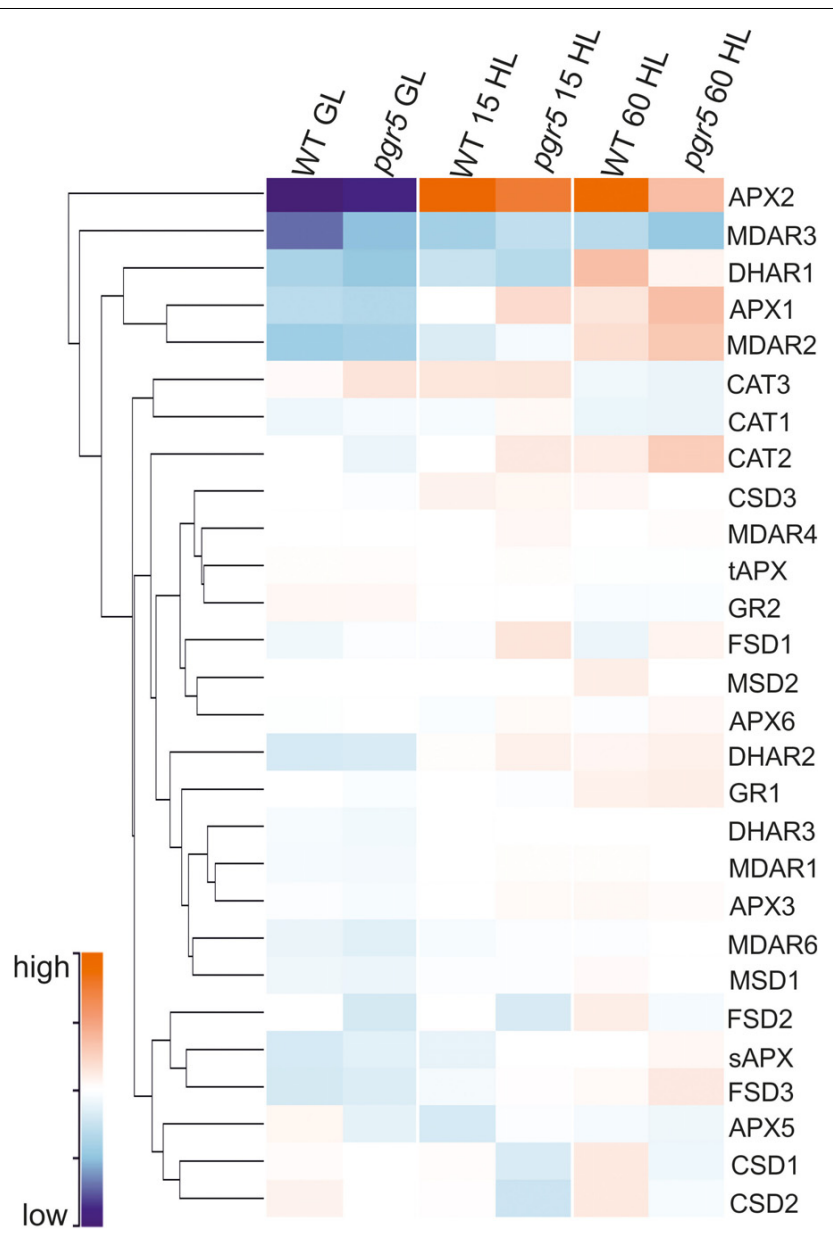

FIGURE 6 | Clustered heatmap showing normalized abundance of transcripts encoding enzymes in the Foyer-Halliwell-Asada cycle. Samples show gene expression in WT and pgr5 mutant plants under growth light (GL; $125 \mu \mathrm{mol}$ $\left.\mathrm{m}^{-2} \mathrm{~s}^{-1}\right)$ and after 15 and $60 \mathrm{~min}$ in high light ( $\mathrm{HL} ; 1,000 \mu \mathrm{mol} \mathrm{m} \mathrm{m}^{-2} \mathrm{~s}^{-1}$ ). Color intensities indicate transcript abundance, according to the key. APX, ascorbate peroxidase; MDAR, monodehydroascorbate reductase; DHAR, dehydroascorbate reductase; CAT, catalase; CSD, Cu/Zn-superoxide dismutase; tAPX, thylakoidal ascorbate peroxidase; GR, glutathione reductase; FSD, Fe-superoxide dismutase; MSD, Mn-superoxide dismutase; SAPX, stromal ascorbate peroxidase. scavengers cannot prevent PSI photoinhibition under conditions of donor/acceptor side imbalance (Sejima et al., 2014; Zivcak et al., 2015a,b; Takagi et al., 2016).

A slower rate of $P_{m}$ decline in pgr5 after $30 \mathrm{~min}$ in $\mathrm{HL}$, and the eventual stabilization of $P_{m}$ after $2 \mathrm{~h}$ (Figure 1), indicated progressive decrease in ROS-induced PSI inactivation induced by decreasing intensity of stromal over-reduction. Again, this could not be attributed to any improvement in stromal ROS scavenging in pgr5 (Figure 5) and was also not associated with decreased abundance of ROS after $1 \mathrm{~h}$ HL (Figure 4). Instead, a slower rate of PSI inhibition was likely directly related to alleviation of electron pressure on stromal acceptors caused by inactivation of PSI electron transport (described in Figure 8). This observation highlights the protective nature of PSI photoinhibition against over-production of ROS in the chloroplast stroma, which has been previously suggested (Tikkanen and Aro, 2014). Furthermore, in the absence of adequate $\mathrm{pH}$-dependent photosynthetic control, as in the pgr5 mutant, the extent of PSI inhibition appears to correlate to the level of imbalance between PSI donor and acceptor sides, which was high during the initial stages of $\mathrm{HL}$ and diminished as PSI inhibition progressed. In this way, PSI photoinhibition can be seen to support PSI donor side regulation in preventing oversupply of reductants to the stromal acceptor side. The idea that PSI photoinhibition is sensitive to the extent of photosynthetic imbalance was also evident in the changes in $\mathrm{CO}_{2}$ assimilation in pgr5 during the HL treatments. A rapid rate of decline during the first $15 \mathrm{~min}$ of HL (Figure 2) corresponded with rapid PSI photoinhibition (Figure 1A), while slower decline during the latter part of the HL treatment correlated with a slower decrease in $P_{m}$ during this phase of treatment. During the second HL treatment, rapid $A$ decline was not observed in pgr5 (Figure 2, 150-180 min), presumably because PSI inhibition from the previous HL exposure had effectively "preset" PSI activity to suit the capacity of stromal acceptors at $1,000 \mu \mathrm{mol}$ photons $\mathrm{m}^{-2} \mathrm{~s}^{-1}$.

Although PSI inhibition can protect against over-production of stromal ROS during conditions of insufficient stromal acceptor capacity, PSI damage is a major impediment to carbon metabolism under normal growth conditions (Gollan et al., 2017; Lima-Melo et al., 2019). In the current study, this was especially
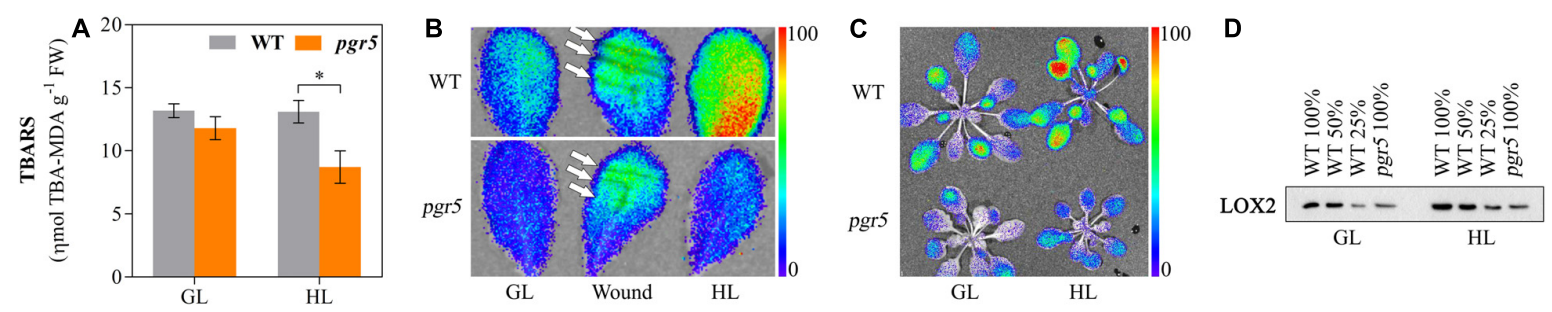

FIGURE 7 | Lipid oxidation in pgr5 mutants after high light treatment. Content of thiobarbituric acid-reactive substances (TBARS; A), autoluminescence imaging (B,C), and Western blotting detection of chloroplast lipoxygenase (LOX2) abundance (D) in WT and pgr5 mutants treated with growth light (GL; $125 \mu$ mol $\mathrm{m}^{-2} \mathrm{~s}^{-1}$ ) and high light $\left(\mathrm{HL} ; 1,000 \mu \mathrm{mol} \mathrm{m} \mathrm{m}^{-2} \mathrm{~s}^{-1}\right)$ for $1 \mathrm{~h}$. Luminescence intensities (B,C) correspond to color scales as shown. Luminescence images overlay photographs of the same leaf/rosette samples. Wounding of leaves is indicated by white arrows in (B). Error bars show standard error among replicates $(n=4)$. Significant differences between treatments and genotypes are indicated by asterisks (Student's $t$-test, $p<0.05$ ). 


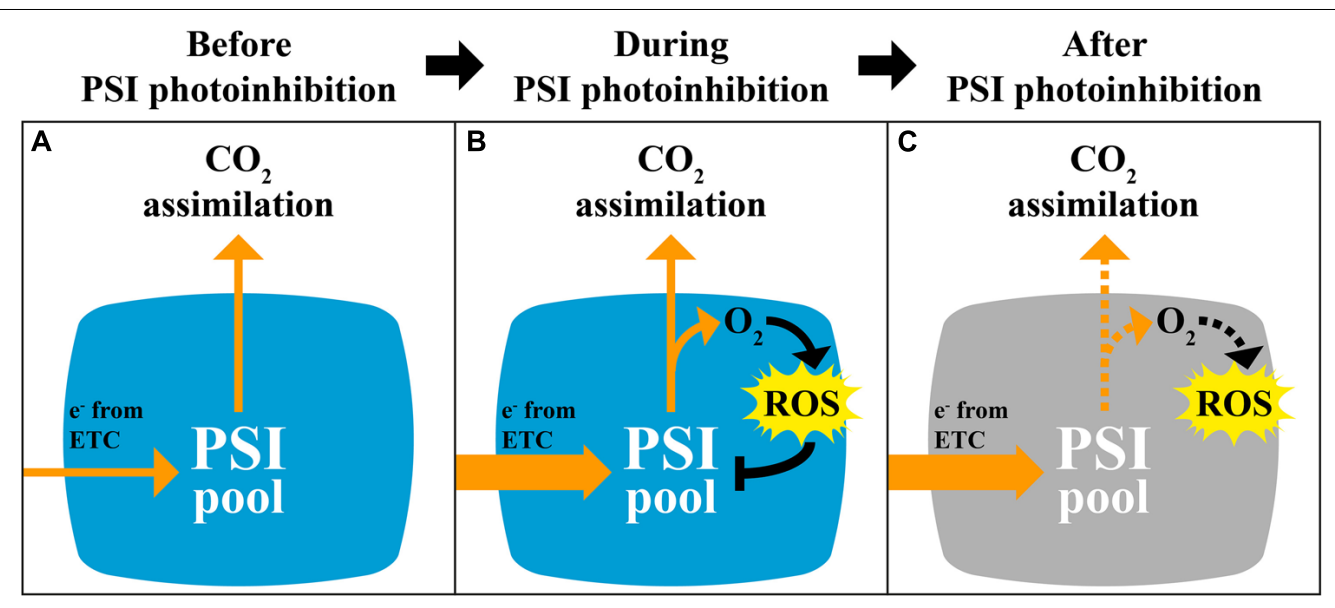

FIGURE 8 | Hypothetical scheme describing the mechanism and impact of PSI photoinhibition on $\mathrm{CO}_{2}$ fixation and ROS production. (A) Under constant conditions, electron pressure at the donor and acceptor sides of PSI is balanced due to partially oxidized state of P700 and stromal electron carriers. Excess ROS production is minimal. (B) During the first minutes of electron imbalance between PSI donor and acceptor sides, such as during exposure of pgr5 mutants to high light, or during low light and cold temperature (Sonoike and Terashima, 1994) or fluctuating light (Kono et al., 2014), limited stromal electron acceptor capacity leads to increased reduction of molecular oxygen. Increased ROS production leads to inactivation of PSI, presumably through oxidation of FeS clusters. (C) Partial inactivation of the PSI pool leads to decreased electron flow to the stroma, which limits the capacity for $\mathrm{CO}_{2}$ fixation, especially under low light, and presumably decreases excess ROS production to protect downstream electron acceptors.

clear in the diminished $\mathrm{CO}_{2}$ fixation in HL-treated pgr5 plants under subsequent GL (Figures 2, 3A). This phenomenon was not due to decreased availability of $\mathrm{CO}_{2}$ in pgr5 leaves, as internal $\mathrm{CO}_{2}$ concentration $\left(C_{i}\right)$ in pgr5 plants was equivalent to WT levels, and higher in HL-treated pgr5 plants. Instead, the light-dependent effect on $A$ in PSI-inhibited plants reflects PSI quantum efficiency, where the highly reduced state of P700 under low light is exacerbated by PSI damage, while more $\mathrm{P}^{+} 0^{+}$is formed under HL due to more active PSI electron transport, in combination with high light-activated electron transport regulation (Baker et al., 2007; Lima-Melo et al., 2019). Despite the positive effects of $\mathrm{HL}, \mathrm{CO}_{2}$ assimilation rates in PSI-inhibited plants remained lower than WT controls during the second HL treatment (Figure 2). Considering these results, we expect that the generation of $\mathrm{O}_{2}^{\bullet-}$ during a subsequent $\mathrm{HL}$ treatment would also have been diminished in plants with inhibited PSI, although this was not specifically tested. Slightly higher stomatal conductance $\left(g_{s}\right)$ in pgr5 mutants compared to WT under GL correlated with higher transpiration rates $(E)$ in the mutant under GL, while lower water use efficiency (WUE) in HL-treated pgr5 reflected low levels of $\mathrm{CO}_{2}$ fixation (Figure 3). Abnormal gas exchange in pgr5 leaves may be related to the influence of plastoquinone (PQ) reduction state on stomatal opening and regulation of WUE in response to light (Busch, 2014; Głowacka et al., 2018), given that over-reduction of the PQ pool has been demonstrated in pgr5 mutants, especially after HL-treatment (Nandha et al., 2007; Munekage et al., 2008; Suorsa et al., 2012; Kono et al., 2014; Gollan et al., 2017; Lima-Melo et al., 2019).

Decreased production $\mathrm{O}_{2}^{\bullet-}$ and $\mathrm{H}_{2} \mathrm{O}_{2}$, generated from $\mathrm{O}_{2}$ reduction and $\mathrm{O}_{2}^{\bullet-}$ dismutation, respectively, was previously observed in pgr5 mutant seedlings exposed to fluctuating light stress (Suorsa et al., 2012). In addition, $\mathrm{H}_{2} \mathrm{O}_{2}$-related gene expression was negatively affected in HL-stressed pgr5 plants
(Gollan et al., 2017). These results were attributed to increased antioxidant capacity in pgr5 (Suorsa et al., 2012) and/or decreased $\mathrm{O}_{2}$ reduction by inactivated PSI (Gollan et al., 2017). However, results of the current study demonstrated that ROS accumulation and oxidative stress after severe PSI photoinhibition was not substantially different from HL-stressed leaves with functional PSI, despite oxidative damage that was seen to occur in both genotypes by increases in electrolyte leakage after HL treatment (Figure 4A). Our results showing no apparent over-accumulation of $\mathrm{H}_{2} \mathrm{O}_{2}$ or $\mathrm{O}_{2}^{\bullet-}$ in HL-treated pgr5 leaves, compared to WT, may differ from previous results because we measured ROS levels after completion of HL treatments, rather than assaying accumulation of ROS during stress treatments (Suorsa et al., 2012). It is likely that foliar $\mathrm{O}_{2}^{\bullet-}$ and $\mathrm{H}_{2} \mathrm{O}_{2}$ contents did increase during the first minutes under HL in both WT and pgr5 plants, but were returned to basal levels during the $1 \mathrm{~h}$ treatment, as has been previously demonstrated (Galvez-Valdivieso et al., 2009; König et al., 2018). Efficient $\mathrm{H}_{2} \mathrm{O}_{2}$ scavenging during $\mathrm{HL}$ relies on the activity of the Foyer-Halliwell-Asada cycle for redox turnover of ascorbate and GSH (reviewed in Foyer and Shigeoka, 2011), which appeared to function normally in HL-treated pgr5 plants according to similar transcript levels and activities of enzymes of the cycle (Figures 5, 6). An exception was DHAR, which showed increased total activity in HL-treated pgr5 leaves, despite the expression of the mitochondrial DHAR1 isoform being significantly downregulated in this condition. DHAR converts DHA to ascorbate using electrons from the reduced form of GSH, suggesting a higher accumulation of DHA in pgr5 during HL stress. Similarly, expression of APX2 was significantly down-regulated in pgr5 after HL treatment, as previously reported (Gollan et al., 2017). Induction of Arabidopsis APX2 expression is dependent on the occurrence of photosynthetic electron transport (Karpiński et al., 1997, 1999; Chang et al., 2004; Galvez-Valdivieso et al., 2009), 
which is lower in the case of severe PSI photoinhibition. Interestingly, the total activity of catalase (CAT) in pgr5 leaves was higher under non-stress conditions than in WT leaves, correlating with increased expression of peroxisomal CAT3 in these conditions.

PSI photoinhibition in pgr5 plants appeared to have a substantial negative effect on lipid oxidation, as measured by quantification of TBARS content and autoluminescence of leaves and rosettes. We previously detected no difference in lipid oxidation between WT and pgr5 plants that were treated with severe high light stress that also caused chlorophyll bleaching in affected leaves of both genotypes (Gollan et al., 2017). In the current study, exposure to $1,000 \mu \mathrm{mol}$ photons $\mathrm{m}^{-2} \mathrm{~s}^{-1}$ for $1 \mathrm{~h}$ did not bleach leaves, and this treatment revealed substantially lower levels of lipid oxidation in pgr5 in comparison to WT. Lipid peroxides can be formed in the chloroplast either non-enzymatically, through the reaction between singlet oxygen $\left({ }^{1} \mathrm{O}_{2}\right)$ and unsaturated lipids (reviewed in Laloi and Havaux, 2015), or enzymatically through the activity of lipoxygenase (LOX) enzymes (reviewed in Wasternack and Hause, 2013). Nonenzymatic lipid peroxidation is associated with ${ }^{1} \mathrm{O}_{2}$ formation in PSII, especially under conditions of PSII over-reduction (Triantaphylidès et al., 2008). PSI photoinhibition is known to increase excitation pressure on PSII (Suorsa et al., 2012; Kono et al., 2014; Lima-Melo et al., 2019), suggesting that higher non-enzymatic lipid oxidation may be expected in HL-treated pgr5. On the contrary, decreases in HL-induced lipid oxidation observed in pgr5 likely relate to the low abundance of chloroplastlocalized lipoxygenase LOX2, which was evident in both GLand HL-treated plants (Figure 7C). Down-regulation of LOX2 suggests disrupted chloroplast signaling in pgr5, which is in line with our previous detection of decreased oxylipin signaling in PSI-photoinhibited pgr5 (Gollan et al., 2017). Indeed, LOX gene expression is induced by oxylipins (Porta et al., 2008; Sarde et al., 2018), while lipid peroxidation is an early step in enzymatic oxylipin synthesis (Wasternack and Hause, 2013), making it difficult to distinguish the cause of low lipid oxidation from the effect in this case. Equivalent luminescence signals were detected in both WT and pgr5 after physical wounding of leaves (Figure 7B), indicating that wound-responsive lipid oxidation pathways were operational in pgr5 plants.

\section{CONCLUSION}

This study shows that PSI photoinhibition is rapidly induced under conditions of imbalanced reduction pressure between PSI donor and acceptor sides, and that PSI photoinhibition is not associated with increases in HL-induced ROS accumulation at the

\section{REFERENCES}

Apel, K., and Hirt, H. (2004). Reactive oxygen species: metabolism, oxidative stress, and signal transduction. Annu. Rev. Plant Biol. 55, 373-399. doi: 10.1146/annurev.arplant.55.031903.14 whole leaf level. It should be noted that the donor/acceptor side imbalance in pgr5 under HL is more severe than that induced by natural conditions like low temperatures or fluctuating light (Terashima et al., 1994; Kono et al., 2014; Lima-Melo et al., 2019). Therefore the extent, and probably the mechanism, of PSI photoinhibition in the pgr5 system can be considered overly severe. Nonetheless, the current results can improve our understanding of PSI inhibition induced by natural stresses, while also underscoring the importance of PGR5-dependent protection of PSI. We present the notion that PSI inactivation prevents ROS over-production and oxidative stress in the chloroplast stroma and in the wider cell. This resembles the protective effect of PSII photodamage that prevents over-reduction of downstream components (Tikkanen et al., 2014; Huang et al., 2016), except that damaged PSII is replenished far more efficiently than damaged PSI (Aro et al., 1993; Scheller and Haldrup, 2005). In light of its slow recovery, PSI protection is often considered to be the main target of photosynthetic regulation mechanisms (Tikkanen et al., 2012; Larosa et al., 2018); however, the current work suggests that PSI is also expendable in the effort to mitigate stromal over-reduction. Considering our recent findings that a partially inhibited PSI pool can support normal $\mathrm{CO}_{2}$ metabolism (Lima-Melo et al., 2019), inactivation of PSI may be more affordable than commonly thought.

\section{DATA AVAILABILITY}

The raw data supporting the conclusions of this manuscript will be made available by the authors, without undue reservation, to any qualified researcher.

\section{AUTHOR CONTRIBUTIONS}

YL-M, E-MA, and PG devised the work. YL-M, VA, AL, RS, and PG conducted the experiments. YL-M, MT, E-MA, JS, and PG analyzed the data. YL-M, E-MA, JS, and PG wrote the manuscript.

\section{FUNDING}

The authors acknowledge financial support from: CAPES (project BEX10758/14-3, YL-M); CIMO (project TM-16-10130, E-MA); CNPq (Proc. 154471/2018-6, AL; INCT Plant Stress Biotech, Proc. 465480/2014-4, JS); FCT-Portugal/FUNCAPBrazil (FUNCAP - FCT AAC No. 02/SAICT/2017, JS); and Academy of Finland (projects 26080341, PG; and 307335 and 303757, E-MA).

Aro, E. M., Virgin, I., and Andersson, B. (1993). Photoinhibition of photosystem II. Inactivation, protein damage and turnover. Biochim. Biophys. Acta 1143, 113-134. doi: 10.1016/0005-2728(93)90134-2

Asada, K. (1999). The water-water cycle in chloroplasts: scavenging of active oxygens and dissipation of excess photons. Annu. Rev. Plant Physiol. Plant Mol. Biol. 50, 601-639. doi: 10.1146/annurev.arplant.50.1.601 
Baker, N. R., Harbinson, J., and Kramer, D. M. (2007). Determining the limitations and regulation of photosynthetic energy transduction in leaves. Plant Cell Environ. 30, 1107-1125. doi: 10.1111/j.1365-3040.2007. 01680.x

Barth, C., Krause, G. H., and Winter, K. (2001). Responses of photosystem I compared with photosystem II to high-light stress in tropical shade and sun leaves. Plant Cell Environ. 24, 163-176. doi: 10.1046/j.1365-3040.2001. 00673.x

Beers, R. F., and Sizer, I. W. (1952). A spectrophotometric method for measuring the breakdown of hydrogen peroxide by catalase. J. Biol. Chem. 195, 133-140.

Birtic, S., Ksas, B., Genty, B., Mueller, M. J., Triantaphylidès, C., and Havaux, M. (2011). Using spontaneous photon emission to image lipid oxidation patterns in plant tissues. Plant J. 67, 1103-1115. doi: 10.1111/j.1365-313X.2011.04646.x

Blum, A., and Ebercon, A. (1981). Cell membrane stability as a measure of drought and heat tolerance in wheat. Crop Sci. 21, 43-47.

Bradford, M. M. (1976). A rapid and sensitive method for the quantification of microgram quantities of protein utilizing the principle of protein-dye binding. Anal. Biochem. 72, 248-254. doi: 10.1016/0003-2697(76)90527-3

Busch, F. A. (2014). Opinion: the red-light response of stomatal movement is sensed by the redox state of the photosynthetic electron transport chain Photosynth. Res. 119, 131-140. doi: 10.1007/s11120-013-9805-6

Chang, C. C.-C., Ball, L., Fryer, M. J., Baker, N. R., Karpiński, S., and Mullineaux, P. M. (2004). Induction of ASCORBATE PEROXIDASE 2 expression in wounded Arabidopsis leaves does not involve known wound-signalling pathways but is associated with changes in photosynthesis. Plant J. 38, 499-511. doi: 10.1111/j.1365-313x.2004.02066.x

Czarnocka, W., and Karpiński, S. (2018). Friend or foe? Reactive oxygen species production, scavenging and signaling in plant response to environmental stresses. Free Radic. Biol. Med. 122, 4-20. doi: 10.1016/j.freeradbiomed.2018. 01.011

de Souza, A., Wang, J.-Z., and Dehesh, K. (2017). Retrograde signals: integrators of interorganellar communication and orchestrators of plant development. Annu. Rev. Plant Biol. 68, 85-108. doi: 10.1146/annurev-arplant-042916-041007

Exposito-Rodriguez, M., Laissue, P. P., Yvon-Durocher, G., Smirnoff, N., and Mullineaux, P. M. (2017). Photosynthesis-dependent H2O2 transfer from chloroplasts to nuclei provides a high-light signalling mechanism. Nat. Commun. 8:49. doi: 10.1038/s41467-017-00074-w

Foyer, C. H., and Shigeoka, S. (2011). Understanding oxidative stress and antioxidant functions to enhance photosynthesis. Plant Physiol. 155, 93-100. doi: 10.1104/pp.110.166181

Galvez-Valdivieso, G., Fryer, M. J., Lawson, T., Slattery, K., Truman, W., Smirnoff, N., et al. (2009). The high light response in Arabidopsis involves ABA signaling between vascular and bundle sheath cells. Plant Cell 21, 2143-2162. doi: 10 . 1105/tpc. 108.061507

Giannopolitis, C. N., and Reis, S. K. (1977). Superoxide dismutases. I. Occurrence in higher plants. Plant Physiol. 59, 309-314. doi: 10.1104/pp.59.2.309

Głowacka, K., Kromdijk, J., Kucera, K., Xie, J., Cavanagh, A. P., Leonelli, L., et al. (2018). Photosystem II subunit $S$ overexpression increases the efficiency of water use in a field-grown crop. Nat. Commun. 9:868. doi: 10.1038/s41467-01803231-x

Gollan, P. J., Lima-Melo, Y., Tiwari, A., and Tikkanen, M. (2017). Interaction between photosynthetic electron transport and chloroplast sinks triggers protection and signalling important for plant productivity. Philos. Trans. R. Soc. B. Biol. Sci. 372:20160390. doi: 10.1098/rstb.2016. 0390

Gururani, M. A., Venkatesh, J., and Tran, L.-S. P. (2015). Regulation of photosynthesis during abiotic stress-induced photoinhibition. Mol. Plant 8, 1304-1320. doi: 10.1016/j.molp.2015.05.005

Havir, E. A., and McHale, N. A. (1987). Biochemical and developmental characterization of multiple forms of catalase in tobacco leaves. Plant Physiol. 84, 450-455. doi: 10.1104/pp.84.2.450

Heath, R. L., and Packer, L. (1968). Photoperoxidation in isolated chloroplasts. I. Kinects and stoichiometry of fatty acid peroxidation. Arch. Biochem. Biophys. 125, 189-198. doi: 10.1016/0003-9861(68)90654-1

Hossain, M. A., Nakano, Y., and Asada, K. (1984). Monodehydroascorbate reductase in spinach chloroplasts and its participation in regeneration of ascorbate for scavenging hydrogen peroxide. Plant Cell Physiol. 25, 385-395.
Huang, W., Yang, Y.-J., Hu, H., and Zhang, S.-B. (2016). Moderate photoinhibition of photosystem II protects photosystem I from photodamage at chilling stress in tobacco leaves. Front. Plant Sci. 7:182. doi: 10.3389/fpls.2016.00182

Huang, W., Zhang, S.-B., and Cao, K.-F. (2010). The different effects of chilling stress under moderate light intensity on photosystem II compared with photosystem I and subsequent recovery in tropical tree species. Photosynth. Res. 103, 175-182. doi: 10.1007/s11120-010-9539-7

Inoue, K., Sakurai, H., and Hiyama, T. (1986). Photoinactivation sites of photosystem I in isolated chloroplasts. Plant Cell Physiol. 27, 961-968.

Ivanov, A. G., Morgan, R. M., Gray, G. R., Velitchkova, M. Y., and Huner, N. P. A. (1998). Temperature/light dependent development of selective resistance to photoinhibition of photosystem I. FEBS Lett. 430, 288-292. doi: 10.1016/s00145793(98)00681-4

Ivanov, A. G., Rosso, D., Savitch, L. V., Stachula, P., Rosembert, M., Oquist, G., et al. (2012). Implications of alternative electron sinks in increased resistance of PSII and PSI photochemistry to high light stress in cold-acclimated Arabidopsis thaliana. Photosynth. Res. 113, 191-206. doi: 10.1007/s11120-012-9769-y

Karpiński, S., Escobar, C., Kaspinska, B., Creissen, G., and Mullineaux, P. M. (1997). Photosynthetic electron transport regulates the expression of cytosolic ascorbate peroxidase genes in Arabidopsis during excess light stress. Plant Cell 9, 627-640. doi: 10.1105/tpc.9.4.627

Karpiński, S., Reynolds, H., Karpinska, B., Wingsle, G., Creissen, G., and Mullineaux, P. (1999). Systemic signaling and acclimation in response to excess excitation energy in Arabidopsis. Science 284, 654-657. doi: 10.1126/science. 284.5414 .654

Kato, Y., Sun, X., Zhang, L., and Sakamoto, W. (2012). Cooperative D1 degradation in the photosystem II repair mediated by chloroplastic proteases in arabidopsis. Plant Physiol. 159, 1428-1439. doi: 10.1104/pp.112.199042

Klughammer, C., and Schreiber, U. (1998). "Measuring P700 absorbance changes in the near infrared spectral region with a dual wavelength pulse modulation system," in Photosynth. Mech. Eff, ed. G. Garab (Dordrecht: Springer), 43574360. doi: 10.1007/978-94-011-3953-3_1008

König, K., Vaseghi, M. J., Dreyer, A., and Dietz, K. J. (2018). The significance of glutathione and ascorbate in modulating the retrograde high light response in Arabidopsis thaliana leaves. Physiol. Plant 162, 262-273. doi: 10.1111/ppl.12644

Kono, M., Noguchi, K., and Terashima, I. (2014). Roles of the cyclic electron flow around PSI (CEF-PSI) and O2-dependent alternative pathways in regulation of the photosynthetic electron flow in short-term fluctuating light in Arabidopsis thaliana.pdf. Plant Cell Physiol. 55, 990-1004. doi: 10.1093/pcp/pcu033

Kudoh, H., and Sonoike, K. (2002). Irreversible damage to photosystem I by chilling in the light: cause of the degradation of chlorophyll after returning to normal growth temperature. Planta 215, 541-548. doi: 10.1007/s00425-0020790-9

Laloi, C., and Havaux, M. (2015). Key players of singlet oxygen-induced cell death in plants. Front. Plant Sci. 6:39. doi: 10.3389/fpls.2015.00039

Larosa, V., Meneghesso, A., La Rocca, N., Steinbeck, J., Hippler, M., and Szabò, I. (2018). Mitochondria affects photosynthetic electron transport and photosensitivity in a green alga. Plant Physiol. 176, 2305-2314. doi: 10.1104/pp.17. 01249

Li, L., Aro, E.-M., and Millar, A. H. (2018). Mechanisms of photodamage and protein turnover in photoinhibition. Trends Plant Sci. 23, 667-676. doi: 10. 1016/j.tplants.2018.05.004

Lima-Melo, Y., Gollan, P. J., Tikkanen, M., Silveira, J. A. G., and Aro, E.-M. (2019). Consequences of photosystem-I damage and repair on photosynthesis and carbon use in Arabidopsis thaliana. Plant J. 97, 1061-1072. doi: 10.1111/tpj. 14177

López, M. A., Vicente, J., Kulasekaran, S., Vellosillo, T., Martínez, M., Irigoyen, M. L., et al. (2011). Antagonistic role of 9-lipoxygenase-derived oxylipins and ethylene in the control of oxidative stress, lipid peroxidation and plant defence. Plant J. 67, 447-458. doi: 10.1111/j.1365-313X.2011.04608.x

McCord, J. M. (2000). The evolution of free radicals and oxidative stress. Am. J. Med. 108, 652-659.

Mittler, R. (2017). ROS are good. Trends Plant Sci. 22, 11-19. doi: 10.1016/j.tplants. 2016.08.002

Mosblech, A., Feussner, I., and Heilmann, I. (2009). Oxylipins: structurally diverse metabolites from fatty acid oxidation. Plant Physiol. Biochem. 47, 511-517. doi: 10.1016/j.plaphy.2008.12.011 
Mueller, S., Hilbert, B., Dueckershoff, K., Roitsch, T., Krischke, M., and Mueller, M. J. (2008). General detoxification and stress responses are mediated by oxidized lipids through TGA transcription factors in Arabidopsis. Plant Cell 20, 768-785. doi: 10.1105/tpc.107.054809

Mullineaux, P. M., Exposito-Rodriguez, M., Laissue, P. P., and Smirnoff, N. (2018). ROS-dependent signalling pathways in plants and algae exposed to high light: comparisons with other eukaryotes. Free Radic. Biol. Med. 122, 52-64. doi: 10.1016/j.freeradbiomed.2018.01.033

Munekage, Y., Hojo, M., Meurer, J., Endo, T., Tasaka, M., and Shikanai, T. (2002). PGR5 is involved in cyclic electron flow around photosystem I and is essential for photoprotection in Arabidopsis. Cell 110, 361-371. doi: 10.1016/s00928674(02)00867-x

Munekage, Y. N., Genty, B., and Peltier, G. (2008). Effect of PGR5 impairment on photosynthesis and growth in Arabidopsis thaliana. Plant Cell Physiol. 49, 1688-1698. doi: 10.1093/pcp/pcn140

Munns, R. (2005). Genes and salt tolerance: bringing them together. New Phytol. 167, 645-663. doi: 10.1111/j.1469-8137.2005.01487.x

Nakano, Y., and Asada, K. (1981). Hydrogen peroxide is scavenged by ascorbate-specific peroxidase in spinach chloroplasts. Plant Cell Physiol. 22, $867-880$.

Nandha, B., Finazzi, G., Joliot, P., Hald, S., and Johnson, G. N. (2007). The role of PGR5 in the redox poising of photosynthetic electron transport. Biochim. Biophys. Acta 1767, 1252-1259. doi: 10.1016/j.bbabio.2007. 07.007

Noctor, G., Reichheld, J. P., and Foyer, C. H. (2018). ROS-related redox regulation and signaling in plants. Semin. Cell Dev. Biol. 80, 3-12. doi: 10.1016/j.semcdb. 2017.07.013

Ogawa, K., Kanematsu, S., and Asada, K. (1997). Generation of superoxide anion and localization of CuZn-superoxide dismutase in the vascular tissue of spinach hypocotyls: their association with lignification. Plant Cell Physiol. 38, 11181126. doi: 10.1093/oxfordjournals.pcp.a029096

Porta, H., Figueroa-Balderas, R. E., and Rocha-Sosa, M. (2008). Wounding and pathogen infection induce a chloroplast-targeted lipoxygenase in the common bean (Phaseolus vulgaris L.). Planta 227, 363-373. doi: 10.1007/s00425-0070623-y

Ramel, F., Birtic, S., Ginies, C., Soubigou-Taconnat, L., Triantaphylidès, C., and Havaux, M. (2012). Carotenoid oxidation products are stress signals that mediate gene responses to singlet oxygen in plants. Proc. Natl. Acad. Sci. U.S.A. 109, 5535-5540. doi: 10.1073/pnas.1115982109

Sarde, S. J., Kumar, A., Remme, R. N., and Dicke, M. (2018). Genome-wide identification, classification and expression of lipoxygenase gene family in pepper. Plant Mol. Biol. 98, 375-387. doi: 10.1007/s11103-018-0785-y

Satoh, M., Tokaji, Y., Nagano, A. J., Hara-Nishimura, I., Hayashi, M., Nishimura, M., et al. (2014). Arabidopsis mutants affecting oxylipin signaling in photooxidative stress responses. Plant Physiol. Biochem. 81, 90-95. doi: 10.1016/j. plaphy.2013.11.023

Scheller, H. V., and Haldrup, A. (2005). Photoinhibition of photosystem I. Planta 221, 5-8.

Schreiber, U., Bilger, W., and Neubauer, C. (1995). "Chlorophyll fluorescence as a nonintrusive indicator for rapid assessment of in vivo photosynthesis," in Ecophysiology of Photosynthesis, 1st Edn, eds E.-D. Schulze and M. M. Caldwell (Berlin: Springer-Verlag), 49-70. doi: 10.1007/978-3-642-79354-7_3

Sejima, T., Takagi, D., Fukayama, H., Makino, A., and Miyake, C. (2014). Repetitive short-pulse light mainly inactivates photosystem I in sunflower leaves. Plant Cell Physiol. 55, 1184-1193. doi: 10.1093/pcp/pcu061

Sharma, P., Jha, A. B., Dubey, R. S., and Pessarakli, M. (2012). Reactive oxygen species, oxidative damage, and antioxidative defense mechanism in plants under stressful conditions. J. Bot. 2012, 1-26. doi: 10.1016/j.plaphy.2016. 05.038

Simkin, A. J., McAusland, L., Lawson, T., and Raines, C. A. (2017). Over-expression of the RieskeFeS protein increases electron transport rates and biomass yield. Plant Physiol. 175, 134-145. doi: 10.1104/pp.17.00622

Sonoike, K. (1995). Selective photoinhibition of photosystem I in isolated thylakoid membranes from cucumber and spinach. Plant Cell Physiol. 36, 825-830. doi: 10.1093/oxfordjournals.pcp.a078827

Sonoike, K. (2011). Photoinhibition of photosystem I. Physiol. Plant 142, 56-64. doi: 10.1111/j.1399-3054.2010.01437.x
Sonoike, K., and Terashima, I. (1994). Mechanism of photosystem-I photoinhibition in leaves of Cucumis sativus L. Planta 194, 287-293. doi: $10.1007 /$ bf01101690

Souza, P. V. L., Lima-Melo, Y., Carvalho, F. E., Reichheld, J.-P., Fernie, A. R., Silveira, J. A. G., et al. (2018). Function and compensatory mechanisms among the components of the chloroplastic redox network. Crit. Rev. Plant Sci. 38, 1-28. doi: 10.1080/07352689.2018.1528409

Suorsa, M., Järvi, S., Grieco, M., Nurmi, M., Pietrzykowska, M., Rantala, M., et al. (2012). PROTON GRADIENT REGULATION5 is essential for proper acclimation of Arabidopsis photosystem I to naturally and artificially fluctuating light conditions. Plant Cell 24, 2934-2948. doi: 10.1105/tpc.112. 097162

Takagi, D., Takumi, S., Hashiguchi, M., Sejima, T., and Miyake, C. (2016). Superoxide and singlet oxygen produced within the thylakoid membranes both cause photosystem I photoinhibition. Plant Physiol. 171, 1626-1634. doi: 10. 1104/pp.16.00246

Takahashi, S., and Murata, N. (2008). How do environmental stresses accelerate photoinhibition? Trends Plant Sci. 13, 178-182. doi: 10.1016/j.tplants.2008. 01.005

Terashima, I., Funayama, S., and Sonoike, K. (1994). The site of photoinhibition in leaves of Cucumis sativus L. At low temperatures is photosystem I, not photosystem II. Planta 193, 300-306.

Thordal-Christensen, H., Zhang, Z., Wei, Y., and Collinge, D. B. (1997). Subcellular localization of $\mathrm{H} 2 \mathrm{O} 2$ in plants. $\mathrm{H} 2 \mathrm{O} 2$ accumulation in papillae and hypersensitive response during the barley-powdery mildew interaction. Plant J. 11, 1187-1194. doi: 10.1046/j.1365-313x.1997.1106 1187.x

Tikkanen, M., and Aro, E.-M. (2014). Integrative regulatory network of plant thylakoid energy transduction. Trends Plant Sci. 19, 10-17. doi: 10.1016/j. tplants.2013.09.003

Tikkanen, M., Grieco, M., Nurmi, M., Rantala, M., Suorsa, M., and Aro, E.-M. (2012). Regulation of the photosynthetic apparatus under fluctuating growth light. Philos. Trans. R. Soc. B Biol. Sci. 367, 3486-3493. doi: 10.1098/rstb.2012. 0067

Tikkanen, M., Mekala, N. R., and Aro, E.-M. (2014). Photosystem II photoinhibition-repair cycle protects photosystem I from irreversible damage. Biochim. Biophys. Acta 1837, 210-215. doi: 10.1016/j.bbabio.2013. 10.001

Tiwari, A., Mamedov, F., Grieco, M., Suorsa, M., Jajoo, A., Styring, S., et al. (2016). Photodamage of iron-sulphur clusters in photosystem I induces nonphotochemical energy dissipation. Nat. Plants 2:16035. doi: 10.1038/nplants. 2016.35

Tjus, S. E., Møller, B. L., and Scheller, H. V. (1998). Photosystem I is an early target of photoinhibition in barley illuminated at chilling temperatures. Plant Physiol. 116, 755-764. doi: 10.1104/pp.116.2.755

Triantaphylidès, C., Krischke, M., Hoeberichts, F. A., Ksas, B., Gresser, G., Havaux, M., et al. (2008). Singlet oxygen is the major reactive oxygen species involved in photooxidative damage to plants. Plant Physiol. 148, 960-968. doi: 10.1104/pp. 108.125690

Wasternack, C., and Hause, B. (2013). Jasmonates: biosynthesis, perception, signal transduction and action in plant stress response, growth and development. An update to the 2007 review in Annals of Botany. Ann. Bot. 111, 1021-1058. doi: 10.1093/aob/mct067

Yamamoto, H., and Shikanai, T. (2019). PGR5-dependent cyclic electron flow protects photosystem I under fluctuating light at donor and acceptor sides. Plant Physiol. 179, 588-600. doi: 10.1104/pp.18. 01343

Yamori, W. (2016). Photosynthetic response to fluctuating environments and photoprotective strategies under abiotic stress. J. Plant Res. 129, 379-395. doi: 10.1007/s10265-016-0816-1

Zhang, S., and Scheller, H. V. (2004). Photoinhibition of photosystem $\mathrm{I}$ at chilling temperature and subsequent recovery in Arabidopsis thaliana. Plant Cell Physiol. 45, 1595-1602. doi: 10.1093/pcp/ pch 180

Zhou, M., Diwu, Z., Panchuk-Voloshina, N., and Haugland, R. P. (1997). A stable nonfluorescent derivative of resorufin for the fluorometric determination of trace hydrogen peroxide: applications in detecting the activity of phagocyte 
NADPH oxidase and other oxidases. Anal. Biochem. 253, 162-168. doi: 10. 1006/abio.1997.2391

Zivcak, M., Brestic, M., Kunderlikova, K., Olsovska, K., and Allakhverdiev, S. I. (2015a). Effect of photosystem I inactivation on chlorophyll a fluorescence induction in wheat leaves: does activity of photosystem I play any role in OJIP rise? J. Photochem. Photobiol. B Biol. 152, 318-324. doi: 10.1016/j.jphotobiol. 2015.08.024

Zivcak, M., Brestic, M., Kunderlikova, K., Sytar, O., and Allakhverdiev, S. I. (2015b). Repetitive light pulse-induced photoinhibition of photosystem I severely affects CO2 assimilation and photoprotection in wheat leaves. Photosynth. Res. 126, 449-463. doi: 10.1007/s11120-015-0121-1
Conflict of Interest Statement: The authors declare that the research was conducted in the absence of any commercial or financial relationships that could be construed as a potential conflict of interest.

Copyright (c) 2019 Lima-Melo, Alencar, Lobo, Sousa, Tikkanen, Aro, Silveira and Gollan. This is an open-access article distributed under the terms of the Creative Commons Attribution License (CC BY). The use, distribution or reproduction in other forums is permitted, provided the original author(s) and the copyright owner(s) are credited and that the original publication in this journal is cited, in accordance with accepted academic practice. No use, distribution or reproduction is permitted which does not comply with these terms. 